\title{
Progranulin Insufficiency Affects Lysosomal Homeostasis in Retinal Pigment Epithelium
}

\author{
KEI TAKAHASHI, SHINSUKE NAKAMURA, MASAMITSU SHIMAZAWA and HIDEAKI HARA \\ Molecular Pharmacology, Department of Biofunctional Evaluation, \\ Gifu Pharmaceutical University, Gifu, Japan
}

\begin{abstract}
Background: Homozygous loss-of-function progranulin gene (GRN) mutation carriers develop adultonset neuronal ceroid lipofuscinosis (NCL), a lysosomal storage disease. Clinically, NCL patients display retinal degeneration and visual dysfunction. However, there is little information about the effects of progranulin dysfunction on lysosomal function of the retinal pigment epithelium (RPE). Materials and Methods: We performed RNA interference knock down of progranulin in primary human RPE (hRPE) cells and observed RPE function and lysosomal activity. Results: Progranulin localized to the lysosome in RPE cells. Loss of progranulin did not affect the biogenesis of lysosomes in RPE cells, while it was necessary for the activation of lysosomal proteases. Furthermore, progranulin deficiency decreased cell viability and disrupted the cell-cell junctions. Conclusion: Our results demonstrate that progranulin insufficiency disturbs lysosomal activity and physiological functions in RPE cells.
\end{abstract}

Progranulin is an evolutionarily conserved glycoprotein, which is highly expressed in numerous tissues, including epithelial cells, neuronal tissue, and immunocytes (1-3). Progranulin has various biological functions, including anti-inflammation, cell survival, tumorigenesis, and proteolysis (4). Homozygous loss-of-function progranulin gene $(G R N)$ mutation carriers completely lose progranulin expression and develop adultonset neuronal ceroid lipofuscinosis (NCL), a lysosomal storage disease $(5,6)$. Gene mutations associated with different NCL types are mostly related to the process of lysosomal degradation, indicating that progranulin is also

This article is freely accessible online.

Correspondence to: Masamitsu Shimazawa, Ph.D., RPh, Molecular Pharmacology, Department of Biofunctional Evaluation, Gifu Pharmaceutical University, 1-25-4 Daigaku-nishi, Gifu 501-1196, Japan. Tel: +81582308126, e-mail: shimazawa@gifu-pu.ac.jp

Key Words: Progranulin, Retinal pigment epithelium, lysosome. involved in lysosomal function (7). Accumulating evidence indicating that progranulin is indispensable for proper lysosomal function is as follows: Extracellular progranulin undergoes endocytosis and intracellular trafficking to reach the lysosomes $(8,9)$. Progranulin expression facilitates lysosomal acidification in HEK293T and SH-SY5Y cells (10) while its deficiency leads to lysosomal dysfunction in microglia of $G R N$-knockout mice $(11,12)$. In addition, loss of progranulin also affects the biogenesis of lysosomes via the activation of transcription factor EB (TFEB) in neurons and microglia (10, 13). These reports support the role of progranulin in regulating the formation and function of lysosomes.

Clinically, NCL patients display retinal degeneration and visual dysfunction, which is accompanied by the accumulation of auto fluorescent aggregates in the retina $(14,15)$. In addition, there are some available transgenic mouse models for most NCLs, and these models show characteristic retinal phenotypes (16-20). Regarding progranulin, some mouse models with progranulin deficiency have been generated, and retinal degeneration and accumulation of auto fluorescent materials have been observed in these mice (21-23). Our previous studies demonstrated photoreceptor degeneration and abnormal astrogliosis in the retinas of progranulin-deficient mice $(24,25)$. These reports suggest that progranulin may be indispensable for maintaining retinal homeostasis.

The retinal pigment epithelium (RPE) is a polarized epithelial monolayer located between the neuronal retina and the choriocapillaris. RPE cells participate in visual reception through the regeneration of visual pigments. In addition, the major roles of the RPE monolayer include regulation of nutrient transportation from the choriocapillaris into the neural retina and disposal of metabolic waste from photoreceptors (26, 27). The phagocytosis-lysosome pathway plays an essential role in RPE cells in digesting the rod and cone outer segments of photoreceptors and maintaining retinal homeostasis (28). In our previous study, we demonstrated that the addition of recombinant progranulin stimulates phagocytosis of RPE cells (29). However, there is little information about the effects of progranulin dysfunction or other NCL-related mutations on the lysosomal function of RPE cells. 
Thus, the purpose of the present study was to determine whether progranulin deficiency has any effect on the lysosomal function of RPE cells. In this study, we performed RNA interference knockdown of progranulin in primary human RPE (hRPE) cells and observed RPE function and lysosomal activity.

\section{Materials and Methods}

Cell cultures. hRPE cells were obtained from Lonza (Morristown, NJ, USA, Cat\# 00194987). The hRPE cells were grown in RtEGM Retinal Pigment Epithelial Cell Growth Medium BulletKit ${ }^{\mathrm{TM}}$ (Lonza, Cat\# 00195409) containing 2\% fetal bovine serum (FBS), gentamicin sulfate/amphotericin -1000, L-glutamine, and basic fibroblast growth factor, according to the manufacturer's protocol. Cultures were maintained at $37^{\circ} \mathrm{C}$ in a humidified atmosphere of 95\% air and $5 \% \mathrm{CO}_{2}$. The cells were passaged every two days. Subconfluent monolayers of hRPE cells from passages 3 to 4 were used in the experiments.

siRNA transfection. To reduce the expression level of human progranulin in hRPE cells, three small interfering RNA (siRNA) sequences targeting GRN (Thermo Fisher Scientific, Waltham, MA, USA, Cat\# 1299003) were used. The following sequences of siRNA were used: sequence \#1, 5'-GCAGACGGGCGAUCCUGCUUCCAAA-3' (sense) and 5'UUUGGAAGCAGGAUCGCCCGUCUGC-3' (antisense); sequence \#2, 5'-GAUGUGAAAUGUGACAUGGAGGUGA-3' (sense) and 5'UCACCUCCAUGUCACAUUUCACAUC-3' (antisense); sequence \#3, 5'-AGAUCGUGGCUGGACUGGAGAAGAU-3' (sense) and 5'AUCUUCUCCAGUCCAGCCACGAUCU-3' (antisense).

Stealth RNAi siRNA Negative Control (Thermo Fisher Scientific, Cat\# 12935200) was used as a negative control for RNA interference.

To evaluate the effect of GRN siRNA knockdown, the cells were cultured in 96- or 24-well plates containing culture medium at $37^{\circ} \mathrm{C}$ for $24 \mathrm{~h}$. Then, the medium was changed to antibiotic-free culture medium and the siRNAs (20 nmol) were transfected into the cells using Lipofectamine ${ }^{\circledR}$ RNAiMAX Reagent (Thermo Fisher Scientific, Cat\# 13778-150) and Opti-MEM ${ }^{\circledR}$ (Thermo Fisher Scientific, Cat\# 31985070). After 48 h of exposure, the medium was replaced with fresh culture medium.

Lysosomal activity assay. To evaluate the lysosomal activity in RPE cells, LysoTracker ${ }^{\mathrm{TM}}$ Red DND-99 (Thermo Fisher Scientific, Cat\# L7528) and DQ ${ }^{\mathrm{TM}}$ Red BSA (Thermo Fisher Scientific, Cat\# D12051) were dissolved in PBS $(500 \mathrm{nM}$ and $100 \mu \mathrm{g} / \mathrm{mL})$ and stored at $4^{\circ} \mathrm{C}$. The cells were incubated with $500 \mathrm{nM}$ LysoTracker ${ }^{\mathrm{TM}}$ Red DND-99 or $10 \mu \mathrm{g} / \mathrm{mL}$ LysoTracker ${ }^{\mathrm{TM}}$ Red DND-99, for $30 \mathrm{~min}$ or $12 \mathrm{~h}$ at $37^{\circ} \mathrm{C}$. Hoechst 33342 solution $(1: 1,000$; Thermo Fisher Scientific, Cat\# H3570) was added 15 min before imaging. Images were taken with All-in-One Fluorescent Microscope (BZ-X710, Keyence, Osaka, Japan). The obtained images were analyzed by ImageJ software (National Institutes of Health, Bethesda, MD, USA).

Immunocytochemistry. hRPE cells were fixed with $2.67 \%$ paraformaldehyde at room temperature for $30 \mathrm{~min}$. After fixing, the cells were incubated with PBS containing $0.2 \%$ Triton X-100 (BioRad Laboratories, Cat\# 1610407) for $30 \mathrm{~min}$, followed by $1 \mathrm{~h}$ in blocking buffer [PBS containing 1\% bovine serum albumin (Nacalai Tesque, Kyoto, Japan, Cat\# 01863-06)]. The samples were incubated with primary antibodies overnight at $4^{\circ} \mathrm{C}$. After three washes with PBS, the cells stained with secondary antibodies and Hoechst 33342 $(1: 1,000$; Thermo Fisher Scientific, Cat\# H3570) in PBS, for $1 \mathrm{~h}$. The following antibodies were used: goat polyclonal anti-progranulin (1:200; R\&D Systems, Minneapolis, MN, USA, Cat\# AF2420), rabbit polyclonal anti-LAMP2 (1:200; Proteintech, Rosemont, IL, USA, Cat\# 66301-1-Ig), rabbit polyclonal anti-occludin (1:200; ATLAS Antibodies, Stockholm, Sweden, Cat\# A75354), mouse monoclonal anti-vimentin (1:200; Santa Cruz Biotechnology, Santa Cruz, CA, USA, Cat\# sc-6260), Alexa Fluor ${ }^{\circledR} 488$ donkey anti-rabbit IgG (1:1000; Thermo Fisher Scientific, Cat\# A21206), Alexa Fluor ${ }^{\circledR}$ 546 donkey anti-mouse IgG (1:1000; Thermo Fisher Scientific, Cat\# A10036), and Alexa Fluor ${ }^{\circledR} 647$ donkey anti-goat IgG (1:1000; Jackson ImmunoResearch, West Grove, PA, USA, Cat\# 705-605147). Images were acquired with All-in-One Fluorescent Microscope (BZ-X710, Keyence, Osaka, Japan).

Western blot analysis. For western blotting, the cells were cultured in 24-well plates. Briefly, the cells were lysed with radioimmunoprecipitation assay buffer (Sigma-Aldrich, St. Louis, MO, USA, Cat\# R0278) containing protease inhibitor and phosphatase inhibitor cocktails. The cell lysate was centrifuged at $12,000 \times g$ for $20 \mathrm{~min}$ at $4^{\circ} \mathrm{C}$, and the protein concentration in the supernatants was measured using the Pierce ${ }^{\mathrm{TM}}$ BCA Protein Assay Kit (Thermo Fisher Scientific, Cat\# 23225). The sample buffer solution (FUJIFILM Wako, Osaka, Japan, Cat\# 196-16142) was added to the supernatants (supernatant:sample buffer solution=3:1) and then boiled for $5 \mathrm{~min}$.

The protein extracts were separated by sodium dodecyl sulfatepolyacrylamide gel electrophoresis, in $5-20 \%$ gradient gels (SuperSep $^{\mathrm{TM}}$ Ace; FUJIFILM Wako, Cat\# 194-15021), and then transferred to a polyvinylidene difluoride membrane (Immobilon-P; Millipore, Billerica, MA, USA, Cat\# IPVH00010). The membranes were incubated with the following primary antibodies overnight at $4^{\circ} \mathrm{C}$ : goat polyclonal anti-progranulin (1:500; R\&D Systems, Cat\# AF2420), rabbit polyclonal anti-occludin (1:500; ATLAS Antibodies, Stockholm, Sweden, Cat\# A75354), rat monoclonal anti-LAMP1 (1:500; Abcam, Cambridge, UK, Cat\# ab25245), goat polyclonal anti-cathepsin D (1:500; R\&D Systems, Cat\# AF1029), rabbit anti-LAMP2 (1:500; Proteintech, Cat\# 66301-1-Ig), and mouse monoclonal anti- $\beta$-actin $(1: 2,000$; Sigma-Aldrich, Cat\# A2228). After incubation with the primary antibodies, the membranes were incubated with the following antibodies for $1 \mathrm{~h}$ at room temperature: horseradish peroxidase (HRP)-conjugated goat anti-rabbit $\operatorname{IgG}$ (1:2,000; Thermo Fisher Scientific, Cat\# 32460), goat anti-mouse IgG (1:2,000; Thermo Fisher Scientific, Cat\# 32430), and rabbit anti-goat $\operatorname{IgG}(1: 2,000$; Thermo Fisher Scientific, Cat\# 31402). The bands were visualized using ImmunoStar ${ }^{\circledR}$ LD (FUJIFILM Wako, Cat\# 290-69904) and then measured using the Amersham Imager 680 (Cytiva, Marlborough, MA, USA).

Cell viability assay. Cellular viability assay was conducted using the Cell Counting Kit 8 (Dojindo Molecular Technologies, Kumamoto, Japan, Cat\# 343-07623). The cells were seeded in 96well plates at a density of 10,000 cells/well. After 48, 72, and $96 \mathrm{~h}$ of siRNA treatment, $10 \mu \mathrm{l}$ of CCK-8 solution was added to each well. The plates were incubated for $1 \mathrm{~h}$ at $37^{\circ} \mathrm{C}$, and then the absorbance was measured at $450 \mathrm{~nm}$ with a reference wavelength of $650 \mathrm{~nm}$ using the Varioskan Flash 2.4 microplate reader (Thermo Fisher Scientific). 

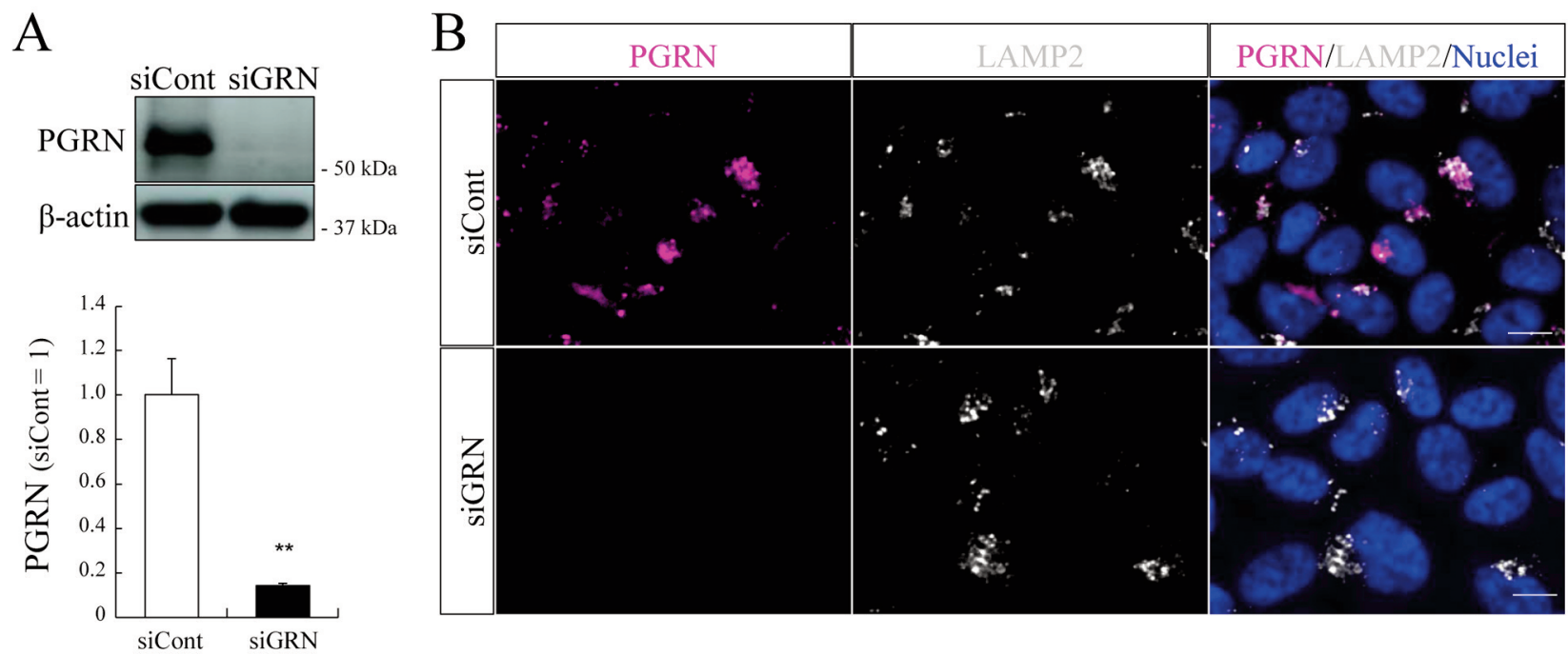

Figure 1. Expression and location of progranulin in human RPE cells. (A) Immunoblotting of cell lysates, obtained from hRPE cells, transfected with either negative control RNA (siControl) or siRNA against progranulin (siGRN). The quantification of progranulin signal was normalized against $\beta$-actin. $n=4$, mean \pm standard error of the mean (S.E.M.). **p<0.01 vs. siControl using Welch's $t$-test (B) Immunostaining for progranulin (magenta) and LAMP2 (white) in siControl- or siGRN-treated cells. Nuclei are stained with Hoechst 33342 (blue). Scale bar=10 $\mu \mathrm{m}$.

Statistical analyses. Data are expressed as the mean \pm standard error of the mean (S.E.M.) of at least four independent wells. Two data sets were compared using a two-tailed Welch's $t$-test. $p$-Values $<0.05$ were considered statistically significant. All statistical tests were conducted using IBM $^{\circledR}$ SPSS $^{\circledR}$ Statistics 24 (IBM, Armonk, NY, USA).

\section{Results}

Progranulin located in lysosome of human RPE cells. To elucidate the expression and location of progranulin in RPE cells, we conducted western blotting and immunostaining after RNA interference with siRNA against progranulin. First, we checked that the efficiency of progranulin knockdown contained the \#1, \#2, or \#3 sequences (data not shown). We chose sequence \#1, which showed the highest efficiency of progranulin knockdown (Figure 1A). Next, the location of progranulin in RPE cell culture was examined by fluorescent immunostaining. Progranulin is a lysosomeresident protein found in several cell types (30). Therefore, we conducted co-immunostaining of progranulin and lysosome-associated membrane protein 2 (LAMP2). In the siControl-treated group, progranulin co-localized with LAMP2, while the signal of progranulin was not detected in siGRN-treated cells (Figure 1B). In contrast, the expression pattern of LAMP2 was not different between the siControland siGRN-treated groups (Figure 1B).

Progranulin-deficiency induces the disruption of the lysosomal function in RPE cells. To evaluate lysosomal activity in progranulin-silenced RPE cells, lysosomal staining with two fluorescent dyes was performed. LysoTracker ${ }^{\mathrm{TM}}$ Red DND-99 is a fluorescent acidotropic probe for labeling and tracking acidic organelles in live cells (31). The fluorescence intensity of LysoTracker dye in the progranulin-silenced hRPE cells was significantly lower than that in the siRNA negative control treated-cells (Figure 2A, B). DQ ${ }^{\text {TM }}$ Red BSA is a fluorogenic substrate for lysosomal proteases that emits strong fluorescence after being disassembled in lysosomes (32). Consistent with the result of LysoTracker dye, the brightness of DQ red dye decreased in siGRN-treated RPE cells compared to control cells (Figure 2C, D).

Progranulin disfunction does not affect the expression level of lysosome-related proteins. In nerve cells and immune cells, including microglia and macrophages, it has been reported that the loss of progranulin leads to overexpression of lysosome-related proteins $(10,33)$. To evaluate the impact of progranulin deficiency on the expression of lysosomal proteins in RPE cells, the expression levels of lysosome-associated membrane proteins (LAMP1 and LAMP2) and lysosomal aspartyl protease (pro- and maturecathepsin D) were compared between siGRN-and siControltreated hRPE cells by western blotting. The expression levels of both LAMP1 and LAMP2 were unaffected by progranulin knockdown (Figure 3A-C). Similarly, the expression levels of pro- and mature-cathepsin D did not change between siControl- and siGRN-treated RPE cells (Figure 3A, D, E). 


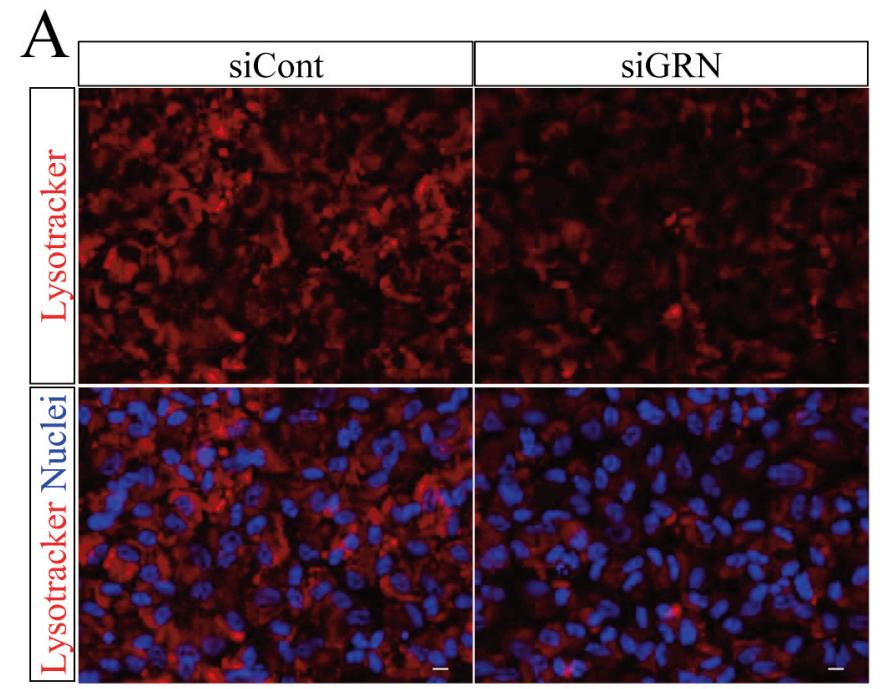

B
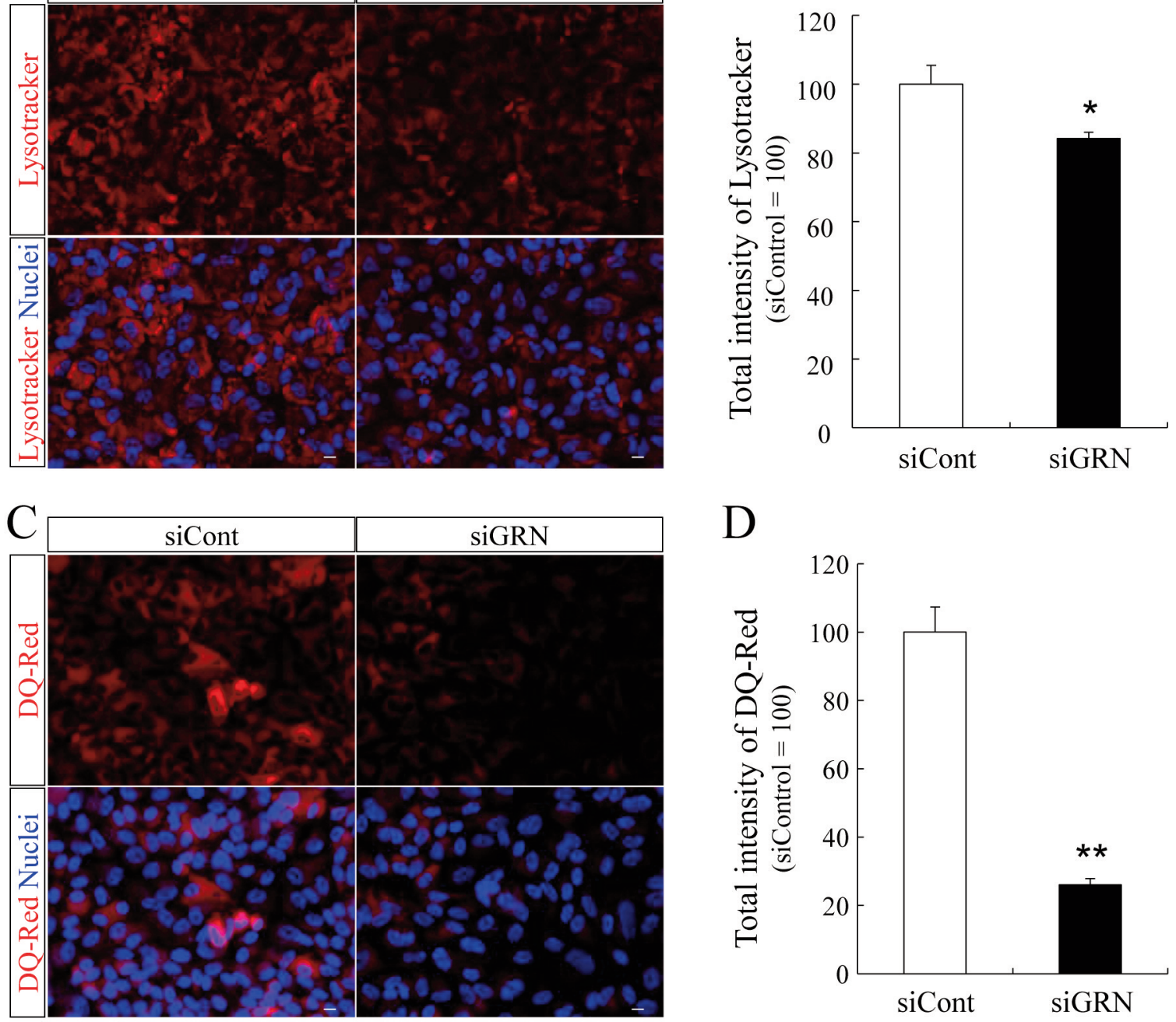

\section{$\mathrm{D}$}

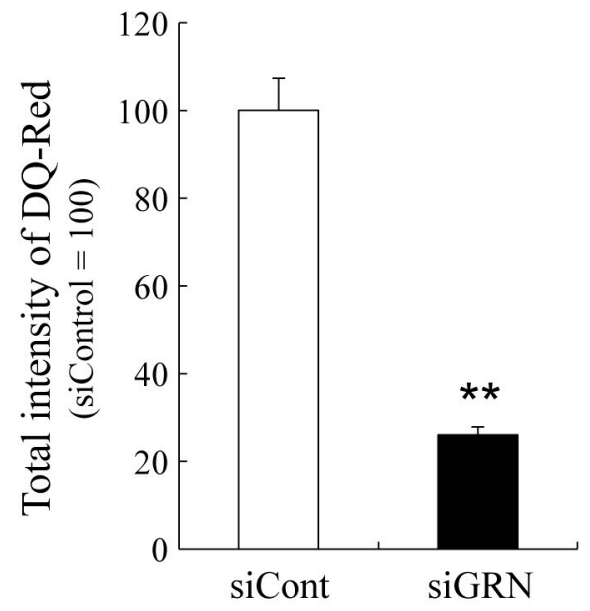

Figure 2. Effects of progranulin-deficiency on lysosomal function of hRPE cells. (A) Representative images of LysoTracker ${ }^{T M}$ Red DND-99 staining (red) and nuclei staining (Hoechst 33342, Blue) of hRPE cells.(B) The fluorescent intensity of LysoTracker ${ }^{T M}$ Red DND-99 in hRPE cells, transfected with negative control RNA or siGRN. (C) Representative images of DQ-Red staining (red) and nuclei staining (Hoechst 33342, Blue) of hRPE cells. (D) Quantitative analysis of the fluorescence intensity of DQ-Red+cells, transfected with negative control RNA or siGRN. $n=6$, mean $\pm S . E . M$. ${ }^{*} p<0.05,{ }^{*} p<0.01$ vs. siControl using Welch's $t$-test. Scale bars $=10 \mu \mathrm{m}$.

Progranulin-deficiency induces the disfunction of RPE cells. To examine the effects of progranulin silencing on hRPE cell function, we determined cell viability. The cell viability of siGRN-treated hRPE cells decreased in a time-dependent manner compared to that of the siRNA negative controltreated cells (Figure 4A). Next, we evaluated the expression pattern of occludin, a typical tight junction protein, in progranulin -silenced RPE cells. The expression level of occludin in siGRN-treated hRPE cells was significantly lower than that in siControl-treated cells (Figure 4B). In addition, progranulin knockdown disrupted occludin integrity, accompanied by changes in the expression pattern of vimentin, a cytoskeletal protein (Figure 4C).

\section{Discussion}

In the current study, we reported that progranulin localized to the lysosome in RPE cells. Additionally, loss of progranulin did not affect the biogenesis of lysosomes in RPE cells, while it was necessary for the activation of lysosomal proteases. Progranulin deficiency decreased cell viability and disrupted the cell-cell junctions. These results 

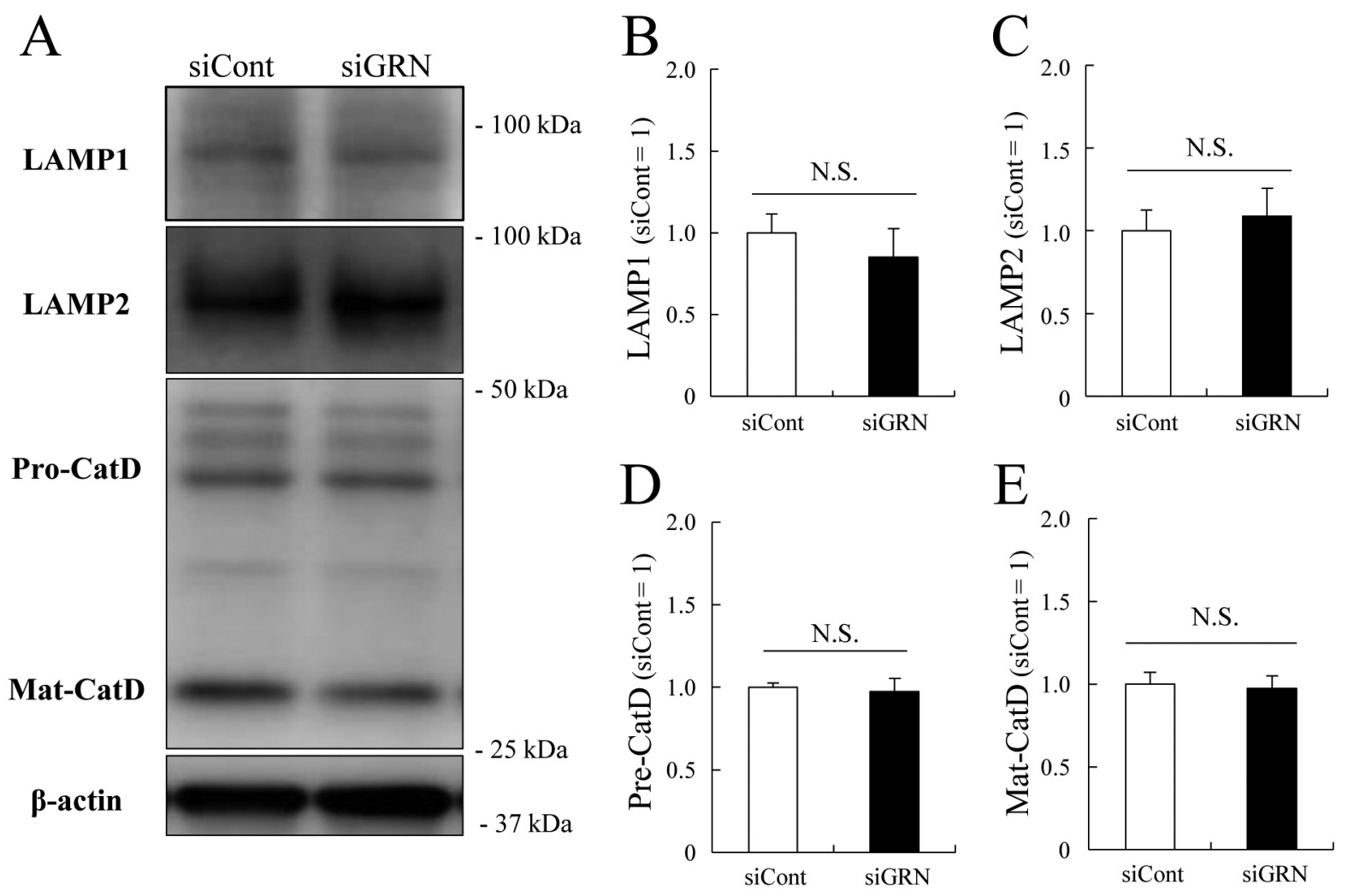

Figure 3. Expression level of lysosomal-related protein in progranulin-deficient hRPE cells. (A) Immunoblotting of LAMP1, LAMP2, CatD, and $\beta$ actin in hRPE cell lysates. (B-E) The expression level of LAMP1 (B), LAMP2 (C), pro-CatD $(D)$ and mat-CatD $(E)$ normalized by $\beta$-actin is shown as the fold-change to siControl-treated hRPE cells. $n=4$, mean \pm S.E.M.

are the first to demonstrate that progranulin dysfunction affects cell function and lysosomal activity in RPE cells.

Progranulin is secreted from various types of cells, including neurons, microglia, macrophages, fibroblasts, and cancer cells (3). In addition, progranulin directly or indirectly binds to trafficking receptors, sortilin, or cation-independent mannose 6-phosphate receptor (CI-M6PR) and is carried to the lysosome $(8,30)$. In the retinal cross section of wild-type mice, high levels of progranulin expression were observed in the RPE layer as well as in the neuronal retina $(24,34)$. However, there was no evidence of the intracellular localization and function of progranulin in RPE cells. We showed that endogenous progranulin in RPE cells was co-localized with lysosomal membrane proteins (Figure 1). This result suggests that progranulin functions as a lysosome-related protein in RPE cells, which is similar to its role in other tissues.

Lysosomes are the major digestive organelles in the RPE cells. They have over 60 acidic hydrolases in their vesicles, each capable of degrading specific substrates (35). Most lysosomal enzymes in the RPE are known to work in a narrow $\mathrm{pH}$ range in the acidic environment of the lysosomal vesicle (36). The normal functioning of lysosomes is necessary to degrade both extracellular (photoreceptor outer segment) and intracellular (autophagy) materials (28). In a previous study, we demonstrated that the addition of progranulin promoted the phagocytic activity of PRE cells (29). It was also reported that the expression of progranulin facilitates acidification of lysosomal vesicles in some cultured cells (10). In the current study, our results showed that the acidity of intracellular vesicles and lysosomal activity were attenuated in progranulin-silenced RPE cells (Figure 2). These findings indicate that progranulin plays an important role in maintaining the acidity of lysosomes in RPE cells. Lysosomal acidification is mainly regulated by vacuolar-type $\mathrm{H}^{+}$-ATPase (V-ATPase), which transports protons across the membrane (37). To date, there is no evidence of a direct interaction between progranulin and VATPase. Further studies are needed to unravel the mechanism by which progranulin maintains lysosomal acidity in RPE cells.

Progranulin insufficiency has been reported to promote the biogenesis of lysosomal proteins in some cultured cells (10, 33). Additionally, lysosomes were enlarged and increased in number in progranulin-deficient mouse cortical neurons (38). 


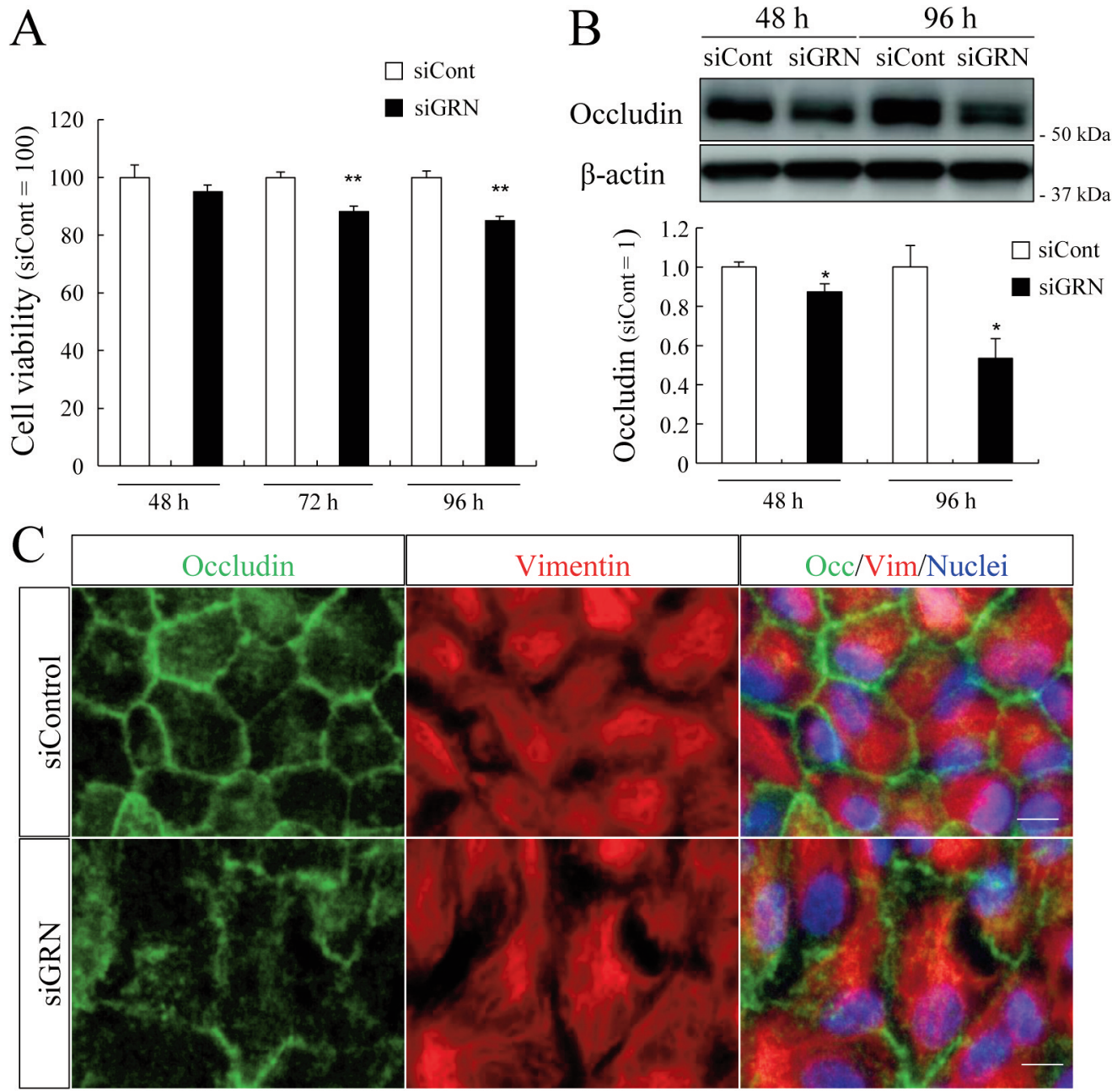

Figure 4. Effects of progranulin-deficiency on cell viability and tight junction of hRPE cells. (A) Quantification of cell viability in hRPE cells exposed to negative control RNA or siGRN at the indicated time point. $n=6$, mean $\pm S . E . M .{ }^{*} p<0.01 \mathrm{vs}$. siControl using Welch's $t$-test. (B) The expression level of occludin normalized by $\beta$-actin is shown as the fold-change to siControl-treated hRPE cell. $n=4$, mean $\pm S . E . M$. $* p<0.05 v s$. siControl using Welch's t-test. (C) Immunostaining of hRPE cells with anti-occludin (green) and anti-vimentin (red) antibodies. Nuclei were stained with Hoechst 33342 (blue). Scale bars $=10 \mu \mathrm{m}$.

However, in the current study, transient progranulin knockdown did not affect the expression level of lysosome proteins in RPE cells (Figure 3). Consistent with the results of the current study, the expression of lysosomal proteins in the RPE-choroid complex was not affected in PGRN knockout mouse (34). Lysosomal dysfunction may result from dysregulation of any of the myriad of proteins required for maintaining lysosomal homeostasis. However, in each case, the disease phenotype and affected tissues can differ (28). The mechanisms by which lysosomal function is regulated in the RPE may be unique. Additionally, some studies suggested that there are some modifier genes which regulate phenotypes of progranulin deficiency. Grn and Tmem106b double knockout mice showed a significant increase of lysosomal proteins in neuron and microglia as compared to wildtype and Grn single knockout mice (39). Nemo-like kinase regulated the expression level of progranulin via lysosomal degradation in microglia, but not through neurons (40). These modifiers might affect the level of lysosome biogenesis in progranulin deficient RPE cells.

Lysosomal dysfunction affects the physiological functions of the RPE. Treatment with the lysosomal alkalizers bafilomycin A1 and chloroquine increases vulnerability to oxidative stress in ARPE-19 cells (41). Likewise, progranulin-deficient RPE cells showed decreased cell viability (Figure 4). In addition, the expression level and distribution of occludin were affected by transient loss of progranulin (Figure 4). These results suggest that progranulin might play an important role in maintaining the normal function of RPE cells. 
In conclusion, our results demonstrate that progranulin insufficiency disturbs lysosomal activity and physiological functions in RPE cells. These findings might help to disentangle the pathological basis of NCL and other retinal degenerative diseases.

\section{Conflicts of Interest}

The Authors have no conflicts of interest to disclose in regard to this study.

\section{Authors' Contributions}

KT, SN, MS, and HH contributed to the conception and design of the study. KT did the acquisition, analysis, and interpretation of data. KT and MS drafted the work and critically revised it. KT, SN, MS, and HH approved the final version to be published. KT, SN, MS, and HH agreed on all aspects of the work.

\section{Acknowledgements}

This study was supported by the Nagai Memorial Research Scholarship from the Pharmaceutical Society of Japan. We thank the members of our laboratory for advice and helpful discussions. We would like to thank Editage (www.editage.com) for English language editing.

\section{References}

1 Kao AW, McKay A, Singh PP, Brunet A and Huang EJ: Progranulin, lysosomal regulation and neurodegenerative disease. Nat Rev Neurosci 18(6): 325-333, 2017. PMID: 28435163. DOI: $10.1038 / \mathrm{nrn} .2017 .36$

2 Palfree RG, Bennett HP and Bateman A: The evolution of the secreted regulatory protein progranulin. PLoS One 10(8): e 0133749 , 2015. PMID: 26248158. DOI: 10.1371/journal.pone.0133749

3 Daniel R, He Z, Carmichael KP, Halper J and Bateman A: Cellular localization of gene expression for progranulin. J Histochem Cytochem 48(7): 999-1009, 2000. PMID: 10858277. DOI: $10.1177 / 002215540004800713$

4 Terryn J, Verfaillie CM and Van Damme P: Tweaking progranulin expression: Therapeutic avenues and opportunities Front Mol Neurosci 14: 713031, 2021. PMID: 34366786. DOI: 10.3389/fnmol.2021.713031

5 Smith KR, Damiano J, Franceschetti S, Carpenter S, Canafoglia L, Morbin M, Rossi G, Pareyson D, Mole SE, Staropoli JF, Sims KB, Lewis J, Lin WL, Dickson DW, Dahl HH, Bahlo M and Berkovic SF: Strikingly different clinicopathological phenotypes determined by progranulin-mutation dosage. Am J Hum Genet 90(6): 11021107, 2012. PMID: 22608501. DOI: 10.1016/j.ajhg.2012.04.021

6 Almeida MR, Macário MC, Ramos L, Baldeiras I, Ribeiro MH and Santana I: Portuguese family with the co-occurrence of frontotemporal lobar degeneration and neuronal ceroid lipofuscinosis phenotypes due to progranulin gene mutation. Neurobiol Aging 41: 200.e1-200.e5, 2016. PMID: 27021778. DOI: $10.1016 /$ j.neurobiolaging. 2016.02.019

7 Cárcel-Trullols J, Kovács AD and Pearce DA: Cell biology of the NCL proteins: What they do and don't do. Biochim Biophys
Acta 1852(10 Pt B): 2242-2255, 2015. PMID: 25962910. DOI: 10.1016/j.bbadis.2015.04.027

$8 \mathrm{Hu}$ F, Padukkavidana T, Vægter CB, Brady OA, Zheng Y, Mackenzie IR, Feldman HH, Nykjaer A and Strittmatter SM: Sortilin-mediated endocytosis determines levels of the frontotemporal dementia protein, progranulin. Neuron 68(4): 654667, 2010. PMID: 21092856. DOI: 10.1016/j.neuron.2010.09.034

9 Zhou X, Sun L, Bastos de Oliveira F, Qi X, Brown WJ, Smolka MB, Sun Y and Hu F: Prosaposin facilitates sortilin-independent lysosomal trafficking of progranulin. J Cell Biol 210(6): 9911002, 2015. PMID: 26370502. DOI: 10.1083/jcb.201502029

10 Tanaka Y, Suzuki G, Matsuwaki T, Hosokawa M, Serrano G, Beach TG, Yamanouchi K, Hasegawa $M$ and Nishihara M: Progranulin regulates lysosomal function and biogenesis through acidification of lysosomes. Hum Mol Genet 26(5): 969-988, 2017. PMID: 28073925. DOI: $10.1093 / \mathrm{hmg} / \mathrm{ddx} 011$

11 Lui H, Zhang J, Makinson SR, Cahill MK, Kelley KW, Huang HY, Shang Y, Oldham MC, Martens LH, Gao F, Coppola G, Sloan SA, Hsieh CL, Kim CC, Bigio EH, Weintraub S, Mesulam MM, Rademakers R, Mackenzie IR, Seeley WW, Karydas A, Miller BL, Borroni B, Ghidoni R, Farese RV Jr, Paz JT, Barres BA and Huang EJ: Progranulin deficiency promotes circuitspecific synaptic pruning by microglia via complement activation. Cell 165(4): 921-935, 2016. PMID: 27114033. DOI: 10.1016/j.cell.2016.04.001

12 Wu Y, Shao W, Todd TW, Tong J, Yue M, Koga S, CastanedesCasey M, Librero AL, Lee CW, Mackenzie IR, Dickson DW, Zhang YJ, Petrucelli L and Prudencio M: Microglial lysosome dysfunction contributes to white matter pathology and TDP-43 proteinopathy in GRN-associated FTD. Cell Rep 36(8): 109581, 2021. PMID: 34433069. DOI: 10.1016/j.celrep.2021.109581

13 Tanaka Y, Matsuwaki T, Yamanouchi K and Nishihara M: Increased lysosomal biogenesis in activated microglia and exacerbated neuronal damage after traumatic brain injury in progranulin-deficient mice. Neuroscience 250: 8-19, 2013. PMID: 23830905. DOI: 10.1016/j.neuroscience.2013.06.049

14 Atiskova Y, Kohlschütter A, Spitzer MS and Dulz S: Ophthalmological manifestations of neuronal ceroid lipofuscinoses (NCL): NCL as diseases of brain and retina-the role of ophthalmologists. Ophthalmologe 118(2): 113-118, 2021. PMID: 33315139. DOI: 10.1007/s00347-020-01282-4

15 Huin V, Barbier M, Bottani A, Lobrinus JA, Clot F, Lamari F, Chat L, Rucheton B, Fluchère F, Auvin S, Myers P, Gelot A, Camuzat A, Caillaud C, Jornéa L, Forlani S, Saracino D, Duyckaerts C, Brice A, Durr A and Le Ber I: Homozygous GRN mutations: new phenotypes and new insights into pathological and molecular mechanisms. Brain 143(1): 303-319, 2020. PMID: 31855245. DOI: 10.1093/brain/awz377

16 Atiskova Y, Bartsch S, Danyukova T, Becker E, Hagel C, Storch $\mathrm{S}$ and Bartsch $\mathrm{U}$ : Mice deficient in the lysosomal enzyme palmitoyl-protein thioesterase 1 (PPT1) display a complex retinal phenotype. Sci Rep 9(1): 14185, 2019. PMID: 31578378. DOI: 10.1038/s41598-019-50726-8

17 Wang QJ, Jung KS, Mohan K and Kleinman ME: Imaging data on characterization of retinal autofluorescent lesions in a mouse model of juvenile neuronal ceroid lipofuscinosis (CLN3 disease). Data Brief 32: 106076, 2020. PMID: 32885002. DOI: 10.1016/j.dib.2020.106076

18 Leinonen H, Keksa-Goldsteine V, Ragauskas S, Kohlmann P, Singh Y, Savchenko E, Puranen J, Malm T, Kalesnykas G, 
Koistinaho J, Tanila H and Kanninen KM: Retinal degeneration in a mouse model Of CLN5 disease is associated with compromised autophagy. Sci Rep 7(1): 1597, 2017. PMID: 28487519. DOI: $10.1038 / \mathrm{s} 41598-017-01716-1$

19 Jankowiak W, Brandenstein L, Dulz S, Hagel C, Storch S and Bartsch U: Retinal degeneration in mice deficient in the lysosomal membrane protein CLN7. Invest Ophthalmol Vis Sci 57(11): 49894998, 2016. PMID: 27654426. DOI: 10.1167/iovs.16-20158

20 Bassal M, Liu J, Jankowiak W, Saftig P and Bartsch U: Rapid and progressive loss of multiple retinal cell types in cathepsin Ddeficient mice-an animal model of CLN10 disease. Cells 10(3): 696, 2021. PMID: 33800998. DOI: 10.3390/cells10030696

21 Ward ME, Chen R, Huang HY, Ludwig C, Telpoukhovskaia M, Taubes A, Boudin H, Minami SS, Reichert M, Albrecht P, Gelfand JM, Cruz-Herranz A, Cordano C, Alavi MV, Leslie S, Seeley WW, Miller BL, Bigio E, Mesulam MM, Bogyo MS, Mackenzie IR, Staropoli JF, Cotman SL, Huang EJ, Gan L and Green AJ: Individuals with progranulin haploinsufficiency exhibit features of neuronal ceroid lipofuscinosis. Sci Trans1 Med 9(385): eaah5642, 2017. PMID: 28404863. DOI: 10.1126/scitranslmed.aah5642

22 Hafler BP, Klein ZA, Jimmy Zhou Z and Strittmatter SM: Progressive retinal degeneration and accumulation of autofluorescent lipopigments in Progranulin deficient mice. Brain Res 1588: 168-174, 2014. PMID: 25234724. DOI: 10.1016/j.brainres.2014.09.023

23 Ward ME, Taubes A, Chen R, Miller BL, Sephton CF, Gelfand JM, Minami S, Boscardin J, Martens LH, Seeley WW, Yu G, Herz J, Filiano AJ, Arrant AE, Roberson ED, Kraft TW, Farese RV Jr, Green A and Gan L: Early retinal neurodegeneration and impaired Ran-mediated nuclear import of TDP-43 in progranulin-deficient FTLD. J Exp Med 211(10): 1937-1945, 2014. PMID: 25155018. DOI: 10.1084/jem.20140214

24 Kuse Y, Tsuruma K, Sugitani S, Izawa H, Ohno Y, Shimazawa $\mathrm{M}$ and Hara H: Progranulin promotes the retinal precursor cell proliferation and the photoreceptor differentiation in the mouse retina. Sci Rep 6: 23811, 2016. PMID: 27030285. DOI: $10.1038 /$ srep23811

25 Kuse Y, Tsuruma K, Mizoguchi T, Shimazawa M and Hara H: Progranulin deficiency causes the retinal ganglion cell loss during development. Sci Rep 7(1): 1679, 2017. PMID: 28490764. DOI: $10.1038 / \mathrm{s} 41598-017-01933-8$

26 Strauss O: The retinal pigment epithelium in visual function. Physiol Rev 85(3): 845-881, 2005. PMID: 15987797. DOI: 10.1152/physrev.00021.2004

27 Lehmann GL, Benedicto I, Philp NJ and Rodriguez-Boulan E: Plasma membrane protein polarity and trafficking in RPE cells: past, present and future. Exp Eye Res 126: 5-15, 2014. PMID: 25152359. DOI: 10.1016/j.exer.2014.04.021

28 Sinha D, Valapala M, Shang P, Hose S, Grebe R, Lutty GA, Zigler JS Jr, Kaarniranta K and Handa JT: Lysosomes: Regulators of autophagy in the retinal pigmented epithelium. Exp Eye Res 144: 46-53, 2016. PMID: 26321509. DOI: 10.1016/j.exer.2015.08.018

29 Murase H, Tsuruma K, Kuse Y, Shimazawa M and Hara H: Progranulin increases phagocytosis by retinal pigment epithelial cells in culture. J Neurosci Res 95(12): 2500-2510, 2017. PMID: 28509387. DOI: $10.1002 /$ jnr.24081

30 Paushter DH, Du H, Feng T and Hu F: The lysosomal function of progranulin, a guardian against neurodegeneration. Acta
Neuropathol 136(1): 1-17, 2018. PMID: 29744576. DOI: 10.1007/s00401-018-1861-8

31 Fogel JL, Thein TZ and Mariani FV: Use of LysoTracker to detect programmed cell death in embryos and differentiating embryonic stem cells. J Vis Exp (68): 4254, 2012. PMID: 23092960. DOI: $10.3791 / 4254$

32 Marwaha R and Sharma M: DQ-Red BSA trafficking assay in cultured cells to assess cargo delivery to lysosomes. Bio Protoc 7(19): e2571, 2017. PMID: 29082291. DOI: 10.21769/Bio Protoc. 2571

33 Takahashi K, Nakamura S, Otsu W, Shimazawa M and Hara H: Progranulin deficiency in Iba- $1^{+}$myeloid cells exacerbates choroidal neovascularization by perturbation of lysosomal function and abnormal inflammation. J Neuroinflammation 18(1): 164, 2021. PMID: 34304733. DOI: 10.1186/s12974-021-02203-1

34 Takahashi K, Nakamura S, Shimazawa M and Hara H: Retinal degeneration and microglial dynamics in mature progranulindeficient mice. Int J Mol Sci 22(21): 11557, 2021. PMID: 34768987. DOI: $10.3390 /$ ijms 222111557

35 Settembre C, Fraldi A, Medina DL and Ballabio A: Signals from the lysosome: a control centre for cellular clearance and energy metabolism. Nat Rev Mol Cell Biol 14(5): 283-296, 2013. PMID: 23609508. DOI: 10.1038/nrm3565

36 Liu J, Lu W, Reigada D, Nguyen J, Laties AM and Mitchell CH: Restoration of lysosomal $\mathrm{pH}$ in RPE cells from cultured human and $\mathrm{ABCA} 4(-/-)$ mice: pharmacologic approaches and functional recovery. Invest Ophthalmol Vis Sci 49(2): 772-780, 2008. PMID: 18235027. DOI: 10.1167/iovs.07-0675

37 Sun-Wada GH, Wada Y and Futai M: Lysosome and lysosomerelated organelles responsible for specialized functions in higher organisms, with special emphasis on vacuolar-type proton ATPase. Cell Struct Funct 28(5): 455-463, 2003. PMID: 14745137. DOI: $10.1247 / \mathrm{csf} .28 .455$

38 Elia LP, Mason AR, Alijagic A and Finkbeiner S: Genetic regulation of neuronal progranulin reveals a critical role for the autophagy-lysosome pathway. J Neurosci 39(17): 3332-3344, 2019. PMID: 30696728. DOI: 10.1523/JNEUROSCI.349817.2019

39 Zhou X, Brooks M, Jiang P, Koga S, Zuberi AR, Baker MC, Parsons TM, Castanedes-Casey M, Phillips V, Librero AL, Kurti A, Fryer JD, Bu G, Lutz C, Dickson DW and Rademakers R: Loss of Tmem106b exacerbates FTLD pathologies and causes motor deficits in progranulin-deficient mice. EMBO Rep 21(10): e50197, 2020. PMID: 32761777. DOI: 10.15252/embr.202050197

40 Dong T, Tejwani L, Jung Y, Kokubu H, Luttik K, Driessen TM and Lim J: Microglia regulate brain progranulin levels through the endocytosis/lysosomal pathway. JCI Insight 6(22): e136147, 2021. PMID: 34618685 . DOI: 10.1172/jci.insight.136147

41 Lee SY, Oh JS, Rho JH, Jeong NY, Kwon YH, Jeong WJ, Ryu WY, Ahn HB, Park WC, Rho SH, Yoon YG, Jeong SY, Choi YH, Kim HY and Yoo YH: Retinal pigment epithelial cells undergoing mitotic catastrophe are vulnerable to autophagy inhibition. Cell Death Dis 5: e1303, 2014. PMID: 24967965. DOI: $10.1038 /$ cddis.2014.266

Received November 4, 2021

Revised December 14, 2021

Accepted December 19, 2021 